\title{
A TECHNIQUE FOR MONITORING ADULT EMERGENCE OF PEZOTHRIPS KELLYANUS FROM THE SOIL
}

\author{
K.J. FROUD
}

\section{HortResearch, Private Bag 92169, Auckland}

Kelly's Citrus thrips (KC thrips), (Pezothrips kellyanus), is currently the most important pest affecting citrus production in New Zealand. It has been suspected, but not confirmed, that KC thrips pupate beneath the soil surface. Californian studies with citrus thrips (Scirtothrips citri) showed emergence traps to be an effective monitoring technique. The trap used in California appeared to be cumbersome and expensive to build so a new trap was designed specifically to monitor $\mathrm{KC}$ thrips emergence. Each trap consisted of a 9 litre black calf feeder bucket with the base removed. A Xerox transparency, marked with a grid pattern, was coated with a thin layer of sticky compound (Tanglefoot) and pinned to the base of the bucket from the outside, with the sticky layer facing inside the bucket. Buckets were placed upside down under thrips infested lemon trees and left for a period of 14 days. Traps in Gisborne $(n=30)$ caught an average of 347 ( $\pm 48.2 \mathrm{SE}$ ) adult $\mathrm{KC}$ thrips, confirming that pupation occurs in the soil.

\section{SAMPLING EARWIGS IN APPLE ORCHARDS}

\author{
S. M. PAWSON ${ }^{1}$, D.M. SUCKLING ${ }^{2}$, G.M. BURNIP ${ }^{2}$ \\ and A.R. GIBB ${ }^{2}$ \\ ${ }^{1}$ Lincoln University, Canterbury \\ ${ }^{2}$ HortResearch, P.O. Box 51, Lincoln
}

\begin{abstract}
Earwigs (Forficulina auricularia) were sampled in apple orchard blocks managed under conventional, integrated or biological fruit production using corrugated cardboard tubes placed on tree trunks for four nights. The tubes made a very effective sampling system where the density of earwigs in tubes reflected the insecticide use pattern and age of blocks. No differences were found between integrated and biological production systems, but numbers were lower in the conventional production system. Differences between treatments were repeatable over the eight sampling occasions. A second inter-orchard trial failed to show any significant differences between treatments. Each orchard had significantly different populations of earwigs indicating that factors specific to each orchard were influencing earwig abundance. Preliminary work with time lapse video techniques showed promising results. Earwigs were observed to move up the trunks at dusk and return down at dawn; of interest was the observation that fewer earwigs returned down the trunk than went up. Earwigs appear to have potential as indicators of sustainability in orchards, because they are ubiquitous and known to be predators of a range of economically important pests, although further work is required in this area. This sampling method could also have potential use in summerfruit, where earwigs have greater significance as pests.
\end{abstract}

